ZOOLOGIA 30 (4): 397-402, August, 2013

http://dx.doi.org/10.1590/S1984-46702013000400005

\title{
Effects of moonlight on the capturability of frugivorous phyllostomid bats (Chiroptera: Phyllostomidae) at different time scales
}

\author{
Marco A. R. Mello ${ }^{1,2,5}$, Elisabeth K. V. Kalko ${ }^{2,3}$ \& Wesley R. Silva ${ }^{4}$ \\ ${ }^{1}$ Departamento de Biologia Geral, Instituto de Ciências Biológicas, Universidade Federal de Minas Gerais. Avenida Antonio \\ Carlos 6627, 31270-901 Belo Horizonte, MG, Brazil. \\ 2 Institut für Experimentelle Ökologie, Universität Ulm, Ulm, Germany. \\ 3 Smithsonian Tropical Research Institute, Balboa, Panama. \\ ${ }^{4}$ Departamento de Zoologia, Universidade Estadual de Campinas, Campinas, Brazil. \\ ${ }^{5}$ Corresponding author. E-mail: marmello@gmail.com
}

\begin{abstract}
Some bat species seem to be lunar phobic, i.e., they avoid flying in bright areas or during bright periods of the night; however, the evidence is still controversial. We think that part of this controversy comes from pooling data on bat captures and moonlight intensity according to broad categories, such as moon phases, which conceal the high variability among nights. Therefore, we used detailed, long-term field data on three phyllostomid bat species, in order to test the hypothesis of lunar phobia at two different time scales: 1) among nights, by pooling data of different nights according to moon phases and testing for differences in the distribution of captures; and 2) within a night, by analyzing the relationship between capturability and moonlight intensity (measured as illuminance) in one-hour intervals for 29 individual nights. Although most captures of the studied bat species occurred in the first half of the night, their activity pattern varied largely among nights, and was not always unimodal as commonly assumed. At the larger time scale, all studied bat species showed evidence of lunar phobia, as they were more frequently captured on dark moon phases. Nevertheless, at the smaller time scale, only Carollia perspicillata (Linnaeus, 1758) was less frequently captured on brighter periods of the night. We propose that the unimodal activity pattern assumed for frugivorous phyllostomid bats may be an artifact of data organization, and that activity and lunar phobia are much more variable than previously assumed.
\end{abstract}

KEY WORDS. Activity; behavior; foraging; lunar phobia; mist netting.

As proposed first by MálagA (1954) and observed in subsequent studies (e.g., Crespo et al. 1972, Esberard 2007), some bat species tend to be less active on brighter nights. MoRRISON (1978) coined the term 'lunar phobia' to explain this behavior: some nocturnal animals avoid brighter periods of the night, in order to reduce predation risk, as their main natural enemies are visually oriented. Lunar phobia has been documented for a wide range of small nocturnal animals, from scorpions (SKUTELSKY 1996) to rodents (Clarke 1983). For bats (Mammalia: Chiroptera), positive (Elangovan \& Marimuthu 2001) and negative (Gannon \& WilLIG 1997) evidence of lunar phobia has been obtained.

This controversy may result from ecological differences among bat species. Most Neotropical bats are subject to a considerable predation pressure (e.g., BARNETT et al. 2007, EsBERARD \& VRcibradic 2007, Molinari et al. 2005) that may affect their naturally slow population dynamics (BARCLAY \& Harder 2003). The response of a bat species to moonlight is probably a tradeoff between predation risk and the need for finding enough food (Saldaña-VÁzQuez \& Munguía-Rosas in press). For example, nectar-drinking and insectivorous bats must adjust their for- aging time to periods when their food is available (LANG et al. 2006), whereas some frugivorous bats avoid foraging during bright periods, probably because their food is more predictable in space and time, and so they can afford waiting (Elangovan \& Marimuthu 2001). Recently, it has been proposed that lunar phobia may be also a function of foraging habitat, as species that forage in open areas are more exposed to predators than species that forage in the forest interior (SALDAÑAVÁzquez \& Munguía-Rosas, in press). There seem to be also differences among data collection methods, as evidence from radio-tracking and mist netting studies, for instance, are sometimes contradictory (THIEs et al. 2006).

Another important issue is how the data are analyzed. In most studies, data from different nights are pooled according to broad categories such as bright $v s$. dark nights, or according to moon phases (e.g., Bork 2006, Esberard 2007, Morrison 1978). However, there is large variability in bat activity among nights and also within the same night (e.g., Aguiar \& Marinho-Filho 2004). Therefore, we aimed at testing the hypothesis of lunar phobia at two different time scales: 1) among nights, i.e., by comparing 
nights of dark $v s$. bright moon phases; and 2) within a night, i.e., by testing for a negative relationship between capturability and illuminance in one-hour intervals of the same night. If phyllostomid bats really avoid brighter nights or periods of the same night, in order to escape predators, we expected a lunar phobic bat species to show this behavior at both time scales.

\section{MATERIAL AND METHODS}

The present study was carried out in the lowland Atlantic Forest of Poço das Antas Biological Reserve (hereafter 'Poço das Antas'), southeastern Brazil (22 $30^{\prime}-22^{\circ} 33^{\prime} \mathrm{S}, 4^{\circ} 15^{\prime}$ $\left.42^{\circ} 19^{\prime} \mathrm{W}\right)$. The reserve has $6,100 \mathrm{ha}$, and the regional climate is tropical humid (SCARANo 2002). Our study area comprises eight small forest remnants locally known as Ilhas dos Barbados. They are located on low hills and surrounded by grasslands and clumps of bracken (Mello et al. 2004).

The most recent inventory of the reserve's mammal fauna was published by BRito et al. (2004), while its flora was listed by Guimarães et al. (1988). Several nocturnal bat predators (Handley et al. 1991, Molinari et al. 2005, Rocha-Mendes \& BIANCON 2009), such as carnivorous bats: Chrotopterus auritus (Peters, 1856) and Phyllostomus hastatus (Pallas, 1767); owls: Tyto alba (Scopoli, 1769) and Speotyto cunicularia (Molina, 1782); opossums: Didelphis aurita (Wied-Neuwied, 1826) and Philander frenata (Olfers, 1818); cats: Leopardus pardalis (Linnaeus, 1758) and Leopardus wiedii (Schinz, 1821); coatis: Nasua nasua (Linnaeus, 1766); and raccoons: Procyon cancrivorous (Cuvier, 1798), are known to occur in Poço das Antas (Brito et al. 2004). There are also several snake species in the area, some of which are known bat predators, such as Boa constrictor Linnaeus, 1758; however, there is no estimate of bat predation pressure in the reserve, except for some occasional reports (e.g., LiRA et al. 2006) and one report from a neighboring reserve (Nogueira et al. 2006).

Fieldwork was carried monthly from February 2000 to September 2001 (except for December 2000, January and May 2001), summing up 29 sampling nights distributed in 17 months (some nights were excluded from the analysis due to heavy rain). Bats were captured using six mist nets per night (7 x $3 \mathrm{~m}$ - Ecotone, Inc., Poland) set across trails that dissected different habitats, ranging from forest interiors and forest edges to grasslands and second-growth.

We used capture data collected under different environmental conditions (i.e., moon phase, air temperature, and cloud cover), to encompass most of the natural variability of the system. Nights of heavy rain were excluded from analysis. The total sampling effort amounted to $43,848 \mathrm{~m}^{2}$.h (area of a net multiplied by the number of nets each night and the total of hours sampled, Straube \& Bianconi 2002). We checked the nets every 30 minutes and recorded the time of capture of each individual bat.

Species were identified using a combination of different keys (Cloutier \& Thomas 1992, Emmons \& Feer 1997, Gannon et al. 1989, VizotTo \& TADDEI 1973). Identifications were confirmed by Marcelo R. Nogueira and vouchers were deposited in the Adriano L. Peracchi Collection at the Federal Rural University of Rio de Janeiro, Brazil.

Each bat was individually marked with a metallic armband (A.C. Hughes, Inc., England). Recaptures within the same night were excluded from the analysis, although recaptures in different months were not. We considered data only for the three most captured species, which had large enough sample sizes for the kind of analysis carried out in this study: Artibeus lituratus (Olfers, 1818), Carollia perspicillata (Linnaeus, 1758), and Sturnira lilium (É. Geoff roy, 1810). They are common and widespread phyllostomid bat species (GARDNER 2008), which play important roles as seed dispersers (Mello et al. 2011).

Several studies have evaluated the effect of moonlight on bat activity by pooling captures according to bright $v s$. dark nights or according to moon phases (e.g., Morrison 1978). This categorization conceals the variability in capturability and moonlight among nights. Therefore, we analyzed our data at two different time scales.

First, we analyzed the effect of moonlight on bat capturability at the moon phase scale (i.e., among nights). We pooled capture data according to moon phase, using the standard classification adopted by Observatório Nacional do Rio de Janeiro: the new moon starts when the Moon is perfectly aligned with the Sun and its non-visible side (from the Earth) is totally illuminated; this phase lasts seven days, and then gives place to the waxing phase, and so on. Then we tested for differences in the distribution of captures among moon phases with adherence chi-squared tests. As the sampling effort differed among moon phases, we corrected this bias by using the number of nights sampled to calculate the expected frequencies used in the chi-squared test. The number of captures was used as a surrogate for bat activity under the assumption that higher flight activity of bats leads to higher capture rates (as in Aguiar \& Marinho-Filho 2004).

Second, we assessed the same relationship at the scale of a single night (i.e., within a night). We divided each night into one-hour intervals, and analyzed each interval as an independent sampling unit. We used illuminance as a continuous measure of moonlight intensity. Illuminance is the amount of sunlight reflected by the Moon, taking into account its position relative to the Earth and the Sun (phase), as well as its position in the sky (elevation), and is expressed as a proportion. J.K.L. Moreira (Observatório Nacional do Rio de Janeiro) provided us with data on illuminance.

We used the number of hours after sunset to characterize the time of capture of each bat; local sunset time ranged from 17:12 (winter) to 18:29 (summer). To test for the relationship between moon illuminance and bat captures, we applied a logarithmic regression: $\mathrm{y}=\mathrm{a}+\mathrm{b} * \ln (\mathrm{x})$. We chose a nonlinear model, because we assumed that captures should first decrease fast as moonlight increases until reaching a plateau with a very low number of captures, as above a given illuminance threshold bright- 
ness would be already too intense. Illuminance values for each time interval were calculated as the arithmetic mean of the values for the beginning and the end of the period.

All statistical analyses followed ZAR (1996) and were carried out in R 2.15.1 and SPSS 20.0 for Mac.

\section{RESULTS}

We captured 1,054 bats of 14 species during this study $\left(36 \pm 28\right.$ bats per night, recaptures included, success $=8.3 \times 10^{-}$ ${ }^{4}$ captures $/$ h. $\mathrm{m}^{2}$ ). This corresponds to $56 \%$ of the known bat fauna of Poço das Antas (25 spp., Brito et al. 2004). Bats of the family Phyllostomidae accounted for nine species and $97 \%$ of all captures (1,019 captures). Three species totalized $93 \%$ of all captures: C. perspicillata represented $77 \%(\mathrm{~N}=816)$, A. lituratus $9 \%(\mathrm{~N}=99$ captures), and S. lilium $6 \%(\mathrm{~N}=68$ captures).

The average $( \pm \mathrm{sd})$ number of captures of phyllostomid bats per night was highly variable, ranging from 1 to 119 (36 \pm 28 , mean $\pm \mathrm{sd}$ ). Most captures of the three study species occurred in the first half of the night (764, i.e. 78\%, Fig. 1). There was large variability in the number of captures among nights for all three species, and a unimodal pattern could not be observed (Table I).

At the among-nights scale, we observed that all three bat species were captured in lower frequency on brighter moon phases, even considering the differences in sampling effort among nights (A. lituratus: $\chi^{2}=9.17, \mathrm{p}=0.03$; C. perspicillata: $\chi^{2}=109.91, \mathrm{p}<0.001 ;$ S. lilium: $\chi^{2}=12.13, \mathrm{p}=0.007$ ) (Fig. 2)

At the within-a-night scale, captures of $C$. perspicillata tended to be lower during periods of higher illuminance $\left(\mathrm{r}^{2}=\right.$ $0.16, \mathrm{p}<0.001)$. In contrast, moon illuminance did not explain the variations in capturability neither for A. lituratus $\left(\mathrm{r}^{2}\right.$ $=0.05, \mathrm{p}=0.11)$ nor S. lilium $\left(\mathrm{r}^{2}=0.01, \mathrm{p}=0.40\right)$ (Fig. 3 ).

\section{DISCUSSION}

In the present study, using detailed, long-term field data, we observed that the capturability of three very common species of frugivorous phyllostomid bats is highly variable among nights, and that evidence of lunar phobia are observed at a large time scale, but not at a smaller scale. In other words, all three studied bat species seem to be lunar phobic, when data are pooled according to moon phases. However, by analyzing one-hour intervals of the same night, only C. perspicillata seems to avoid brighter periods of the night.

First, considering the main forces that supposedly explain lunar phobia in bats, i.e., variations in food availability and predator escape (Saldaña-VÁzQuez \& Munguía-Rosas, in press), we can readily discard the former, as all three studied species are primary frugivores that depend on fruits for living (Mello et al. 2011). The main fruit genera on which these bat species depend - Cecropia Loefl., Ficus L., and Piper L., (Lobova et al. 2009) produce ripe fruits in the beginning of the night;
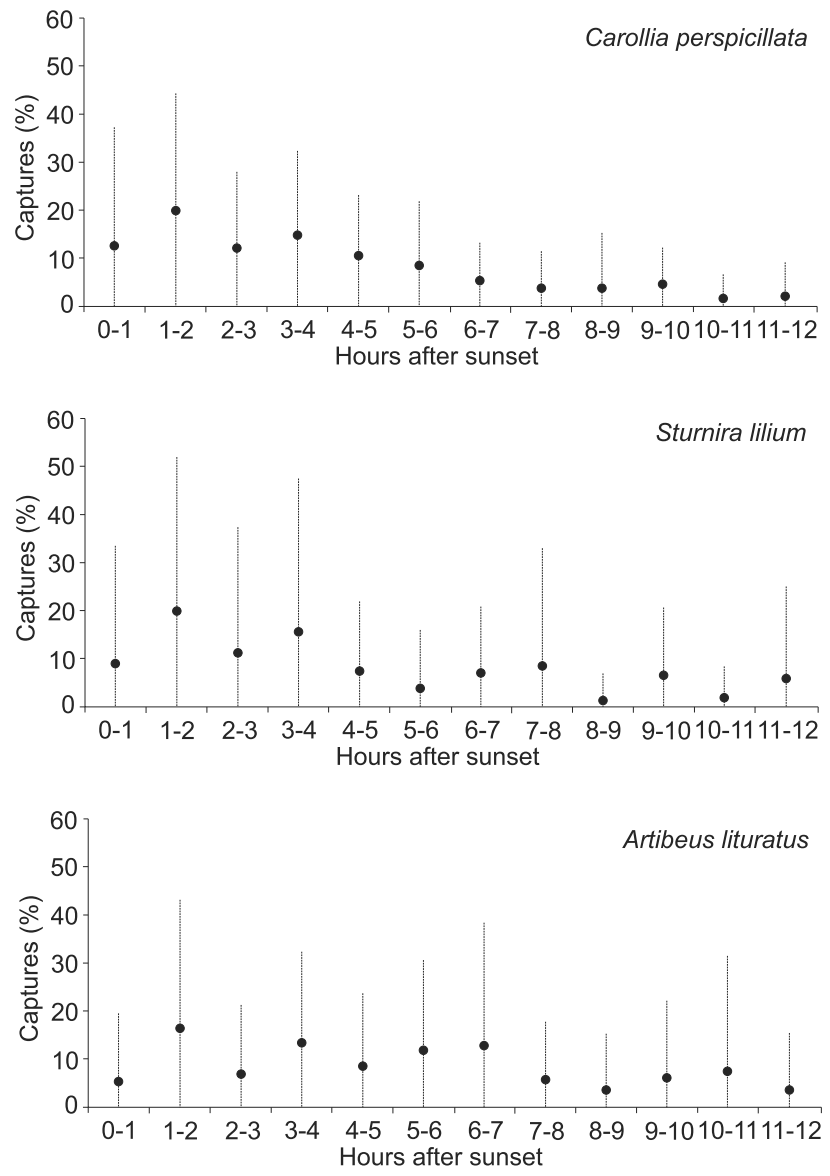

Figure 1. Variation in the number of captures of the bats Artibeus lituratus, Carollia perspicillata, and Sturnira lilium, in relation to onehour periods of 29 nights, in the Poço das Antas Biological Reserve, southeastern Brazil. The number of captures of the three studied bat species varied largely among nights. The variability in capturability among nights is represented as mean (center dots) and standard deviation (vertical dashed lines).

thus, there is no change in food availability for these bats caused by changes in moonlight.

It could be that bats move to darker parts of the environment, such as forest interiors, when the night is brighter (GANNON $\&$ WILLIG 1997). Although this may be true for some bat species, such a change of foraging habitat would be restrained by the spatial distribution of the main food-plants of a bat species. In other words, in the area, the main fruits eaten by C. perspicillata (Piper) and S. lilium (Solanum) (Lobova et al. 2009, Marinho-Filho 1991) are both more abundant on forest edges. Therefore, these two bat species need to forage mainly in these habitats, and would probably not find enough fruits in the forest interior. The same is true for A. lituratus, which focuses on Cecropia and Ficus (Loвova et al. 2009), as this species is a canopy forager that searches for fruits of 
Table I. Variation in the number of captures of the bats Artibeus lituratus, Carollia perspicillata, and Sturnira lilium, in relation to one-hour periods of 29 nights, in the Poço das Antas Biological Reserve, southeastern Brazil. The number of captures of the three studied bat species was highly variable within and among nights (mean $\pm \mathrm{sd}$, minimum/maximum). Number of nights sampled: Artibeus lituratus $=18$, Carollia perspicillata $=29$, Sturnira lilium $=19$. The capture period is expressed as hours after local sunset.

\begin{tabular}{|c|c|c|c|c|c|c|c|c|c|}
\hline \multirow{2}{*}{ Capture period } & \multicolumn{3}{|c|}{ Artibeus lituratus } & \multicolumn{3}{|c|}{ Carollia perspicillata } & \multicolumn{3}{|c|}{ Sturnira lilium } \\
\hline & mean & sd & $\min -\max$ & mean & sd & $\min -\max$ & mean & sd & $\min -\max$ \\
\hline 00-01 & 2.0 & 1.7 & $1-4$ & 6.1 & 8.5 & $1-24$ & 1.0 & 0.0 & $1-1$ \\
\hline 01-02 & 2.3 & 2.6 & $1-8$ & 6.8 & 5.0 & $1-25$ & 2.1 & 1.2 & $1-4$ \\
\hline $02-03$ & 1.8 & 1.0 & $1-3$ & 3.8 & 5.9 & $1-21$ & 1.8 & 1.5 & $1-4$ \\
\hline $03-04$ & 2.7 & 1.8 & $1-6$ & 5.2 & 5.2 & $1-16$ & 1.2 & 0.4 & $1-2$ \\
\hline $04-05$ & 2.0 & 1.2 & $1-4$ & 4.7 & 5.3 & $1-18$ & 1.6 & 0.5 & $1-2$ \\
\hline $05-06$ & 2.2 & 2.4 & $1-7$ & 7.5 & 7.0 & $1-28$ & 1.5 & 0.7 & $1-2$ \\
\hline $06-07$ & 1.3 & 0.5 & $1-2$ & 5.1 & 6.0 & $1-18$ & 1.4 & 0.5 & $1-2$ \\
\hline $07-08$ & 3.0 & 2.0 & $1-5$ & 2.2 & 2.2 & $1-13$ & 1.0 & 0.0 & $1-1$ \\
\hline 08-09 & 1.5 & 0.7 & $1-2$ & 2.5 & 2.4 & $1-9$ & 2.0 & 0.0 & $2-2$ \\
\hline $09-10$ & 1.0 & 0.0 & $1-1$ & 2.6 & 1.9 & $1-10$ & 1.2 & 0.4 & $1-2$ \\
\hline $10-11$ & 1.0 & 0.0 & $1-1$ & 3.0 & 2.0 & $1-6$ & 1.0 & 0.0 & $1-1$ \\
\hline $11-12$ & 1.0 & 0.0 & $1-1$ & 5.0 & 0.0 & $2-7$ & 2.5 & 2.1 & $1-4$ \\
\hline
\end{tabular}
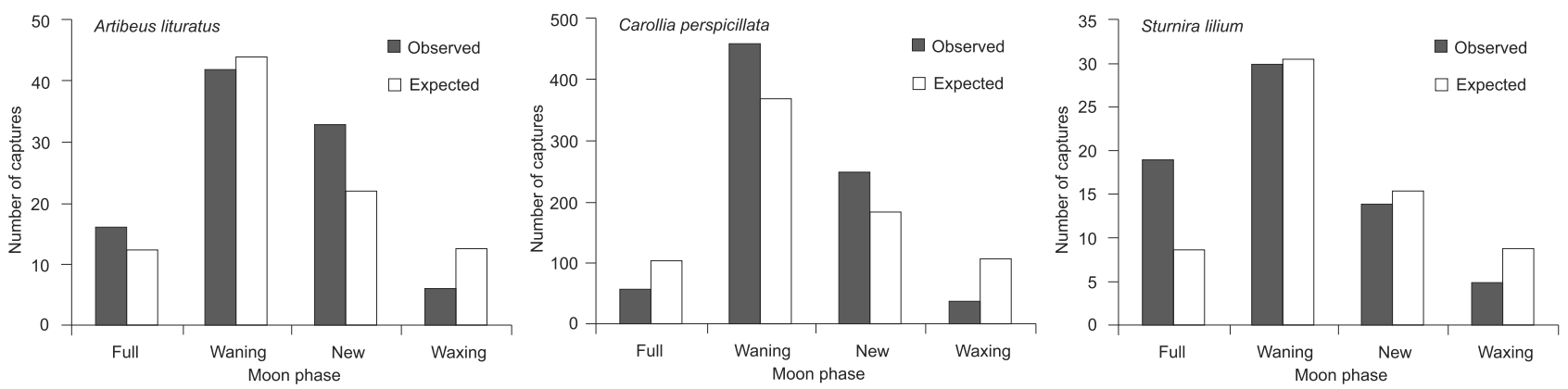

Figure 2. Variation in the number of captures of the bats Artibeus lituratus, Carollia perspicillata, and Sturnira lilium, in relation to moon phases, in the Poço das Antas Biological Reserve, southeastern Brazil. At this "among nights" scale, bats of all three studied species were captured more frequently on darker moon phases, even considering differences in sampling effort among moon phases.

isolated trees in the forest interior but also in open areas and forest edges. Therefore, $A$. lituratus would be the only species for which a change of habitat could occur as a result of lunar phobia. But we sampled different kinds of environment in our study, both open and closed, and the only species with evidence of lunar phobia at the scale of a single night was C. perspicillata. Therefore, differences in foraging habitat do not seem to explain the differences in lunar phobia observed among the studied species.

Alternatively, the differences in capturability observed among moon phases may result from predator escape, especially considering that the study area contains several natural enemies of bats. It remains to be investigated how strong is predator pressure for phyllostomid bats in Poço das Antas. Nevertheless, we can assume that it is strong enough to affect at least some bat species, as several potential bat predators have been recorded in the area and one record of predation of $C$. perspicillata by a car- nivorous bat, C. auritus, has been made in the neighboring União Biological Reserve (Nogueira et al. 2006). Anyway, as already mentioned, it is hard to explain the differences in lunar phobic behavior observed among these three bat species, when considering a finer time scale. It could be that a negative relationship between capturability and illuminance for $C$. perspicillata could be observed, because the sample size for this species was large enough. If this is true, larger samples would be needed to observe a similar effect also for $A$. lituratus and S. lilium. We should also consider that both C. perspicillata and S. lilium forage mainly on shrubs and treelets of the genera Piper and Solanum, respectively (Lobova et al. 2009, Marinho-Filho 1991), which occur more frequently on forest edges but also in the forest interior. Therefore, the only ecological difference that could explain the former being lunar phobic at a small time scale, but not the latter, would be Piper being more abundant on forest edges than Solanum, 

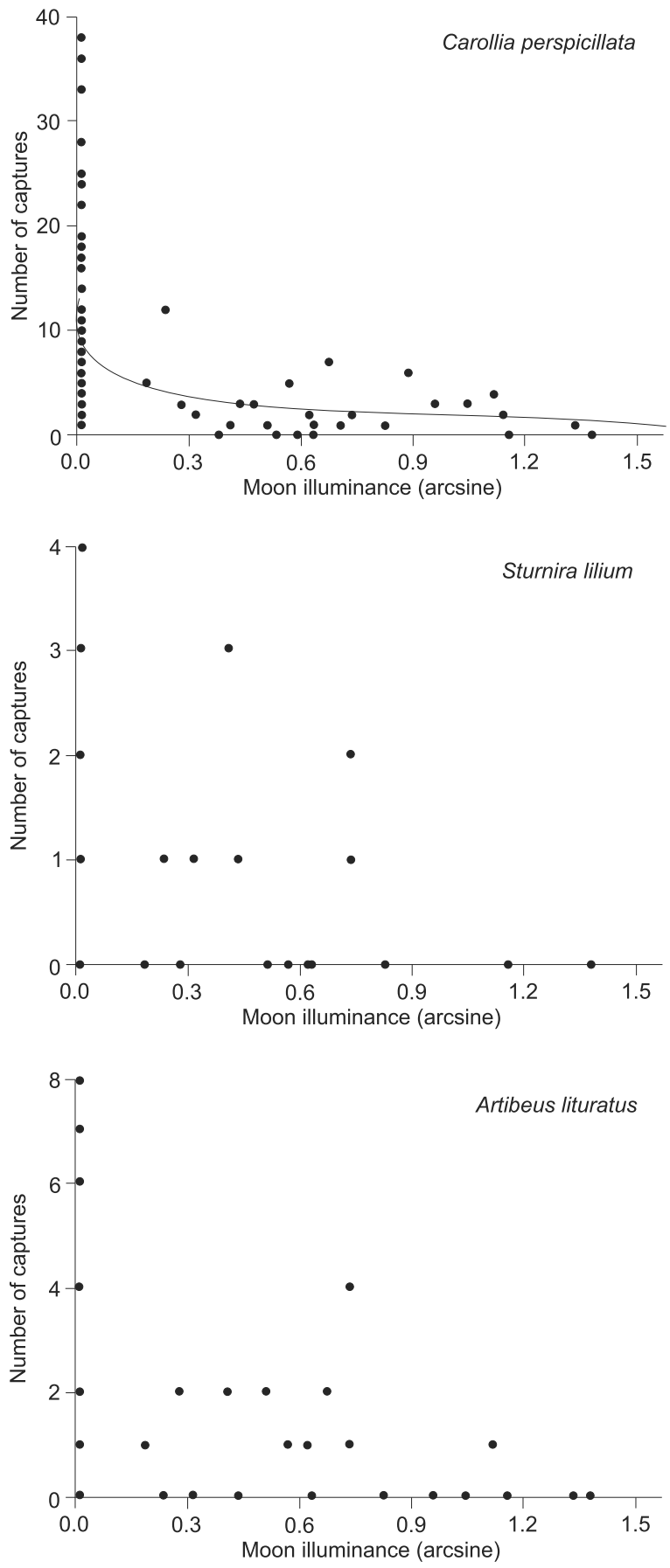

Figure 3. Variation in the number of captures of the bats Artibeus lituratus, Carollia perspicillata, and Sturnira lilium, in relation to moon illuminance in one-hour periods of 29 nights, in the Poço das Antas Biological Reserve, southeastern Brazil. this "within a night" scale, only the bat species C. perspicillata was captured less frequently in brighter periods of the night; there was no similar effect for the other two species. which would cause Carollia bats to be more exposed to visuallyoriented predators. Among the three studied bat species, the one that potentially has the strongest tendency to be lunar phobic would be A. lituratus, as it forages mainly in exposed habitats, considering the general patterns pointed out in a recent meta-analysis (Saldaña-VÁzquez \& Munguía-Rosas, in press); however, our data do not support this hypothesis. In addition, $A$. lituratus is much larger than C. perspicillata and S. lilium (GARDNER 2008), which could lead to a lower predation pressure, detectable only with a larger sample size.

In summary, our findings point out that the activity of frugivorous phyllostomids is highly variable within and among nights, and that evidence of lunar phobia may be observed at larger temporal scales, but not at smaller scales. This might be one simple explanation for the contradictory results obtained in mist netting $v s$. radiotracking studies, whose results are usually analyzed at a large and a small time scale, respectively. In order to further understand the phenomenon of lunar phobia in phyllostomid bats, it is necessary to assess the predation pressure in the study area, in order to test how it balances with food availability and energy requirements on a few nights or within a single night. We also recommend that future studies do not conceal the within- and among-night variability in bat activity, as important clues to the underlying mechanisms of lunar phobia may be obtained with this approach.

\section{ACKNOWLEDGMENTS}

We are very grateful to many people who helped us in this study. Ivan Sazima, James Roper, Mauro Galetti, Marcelo Nogueira, João Vasconcellos-Neto, and Ariovaldo Cruz-Neto made important suggestions to earlier versions of the manuscript. João Moreira provided us with the worksheet for illuminance calculation. Fernando Fernandez helped us with fieldwork infrastructure. IBAMA, especially Dionisio Pessamilio and Rodrigo Mayerhofer, allowed us to work at Poço das Antas. This work was supported by grants to MARM from the Lincoln Park Zoo, Rio de Janeiro Research Foundation (Faperj, E-26/150.662/2000), São Paulo Research Foundation (Fapesp, 02/09286-0), German Academic Exchange Service (DAAD, 290088/2004-6), Alexander von Humboldt Foundation (AvH, 1134644), and Federal University of Minas Gerais.

\section{LITERATURE CITED}

Aguiar, L.M.S. \& J.S. Marinho-Filho. 2004. Activity patterns of nine phyllostomid bat species in a fragment of the Atlantic Forest in southeastern Brazil. Revista Brasileira de Zoologia 21 (2): 385-390.

Barclay, R.M.R. \& L.D. HaRder. 2003. Life histories of bats: life in the slow lane, p. 209-256. In: T.H. Kunz \& M.B. Fenton (Eds). Bat ecology. Chicago, The University of Chicago Press. Barnett, A.; V. Schiel \& A. Deveny. 2007. Corallus hortulanus 
(Amazon tree boa): Bat predation in Jau National Park, Brazil. Herpetological Bulletin (100): 35-37.

Bork, K.S. 2006. Lunar phobia in the greater fishing bat Noctilio leporinus (Chiroptera: Noctilionidae). Revista de Biologia Tropical 54 (4): 1117-1123.

Brito, D.; L.C. Oliveira \& M.A.R. Mello. 2004. An overview of mammalian conservation at Poço das Antas Biological Reserve, southeastern Brazil. Journal for Nature Conservation 12: $219-228$.

Clarke, J.A. 1983. Moonlight's influence on predator/prey interactions between short-eared owls (Asio flammeus) and deermice (Peromyscus maniculatus). Behavioral Ecology and Sociobiology 13: 205-209.

Cloutier, D. \& D.W. Thomas. 1992. Carollia perspicillata. Mammalian Species 417: 1-9.

Crespo, R.F.; S.B. Linhart; R.J. Burns \& C.G. Mitchell. 1972. Foraging behaviour of the common vampire bat related to moonlight. Journal of Mammalogy 53 (2): 366-368.

Elangovan, V. \& G. Marimuthu. 2001. Effect of moonlight on the foraging behaviour of a megachiropteran bat Cynopterus sphinx. Journal of Zoology 253: 347-350.

Emmons, L.H. \& F. FeER. 1997. Neotropical rainforest mammals: a field guide. Chicago, The University of Chicago Press, 396p.

ESBERARD, C.E.L. 2007. Influence of moon cycle in phyllostomid bat capture. Iheringia, Série Zoologia, 97 (1): 81-85.

Esberard, C.E.L. \& D. VRCibradic. 2007. Snakes preying on bats: new records from Brazil and a review of recorded cases in the Neotropical region. Revista Brasileira de Zoologia 24 (3): 848-853.

Gannon, M.; M. Willig \& J. Jones. 1989. Sturnira lilium. Mammalian Species 333: 1-5.

Gannon, M.R. \& M.R. Willig. 1997. The effect of lunar illumination on movement and activity of the red fig-eating bat (Stenoderma rufum). Biotropica 29 (4): 525-529.

Gardner, A.L. 2008. Mammals of South America, volume 1: marsupials, xenarthrans, shrews, and bats. Chicago, University Of Chicago Press, 669p.

Guimarães, E.F.; L. Mautone \& A. Mattos-Filho. 1988. Considerações sobre a floresta pluvial baixo-montana. Boletim da Fundação O Boticário de Proteção à Natureza 23: 45-54.

Handley, C.; D. Wilson \& A. Gardner. 1991. Demography and natural history of the common fruit bat, Artibeus jamaicensis, on Barro Colorado Island, Panama. Smithsonian Contributions to Zoology 511: 1-173.

Lang, A.B.; E.K.V. Kalko; H. Römer; C. Bockholdt \& D.K.N. Dechmann. 2006. Activity levels of bats and katydids in relation to the lunar cycle. Oecologia 146: 659-666.

Lira, P.K.; H.S.A. Carlos; P.L. Curzio \& F.A.S. Fernandez. 2006. Boa constrictor constrictor and Bothrops jararaca. Diet. Herpetological Review 36 (4): 456-456.

Lobova, T.A.; C.K. Geiselman \& S.A. Mori. 2009. Seed dispersal by bats in the Neotropics. New York, New York Botanical Garden Press, 465p.
Málaga, A. 1954. El vampiro portador de la rabia. Boletín de la Oficina Sanitaria Panamericana 37: 53-65.

Marinho-Filho, J.S. 1991. The coexistence of two frugivorous bat species and the phenology of their food plants in Brazil. Journal of Tropical Ecology 7: 59-67.

Mello, M.A.R.; G.M. Schittini; P. Selig \& H.G. Bergallo. 2004. A test of the effects of climate and fruiting of Piper species (Piperaceae) on reproductive patterns of the bat Carollia perspicillata (Phyllostomidae). Acta Chiropterologica 6 (2): 309-318.

Mello, M.A.R.; F.M.D. Marquitti; P.R. Guimarães Jr; E.K.V. Kalko; P. Jordano \& M.A.M. de Aguiar. 2011. The missing part of seed dispersal networks: structure and robustness of batfruit interactions. PLOS One 6 (2): e17395. 10.1371/ journal.pone.0017395: 10.1371/journal.pone.0017395.

Molinari, J.; E.E. Gutierrez; A.A. Ascenção; A. Arends \& R.J. MArquis. 2005. Predation by giant centipedes, Scolopendra gigantea, on three species of bats in a venezuelan cave. Caribbean Journal of Science 41 (2): 340-346.

Morrison, D.W. 1978. Lunar phobia in a Neotropical fruit bat, Artibeus jamaicensis (Chiroptera: Phyllostomidae). Animal Behaviour 26: 852-855.

Nogueira, M.R.; L.R. Monteiro \& A.L. Peracchi. 2006. New evidence of bat predation by the woolly false vampire bat Chrotopterus auritus. Chiroptera Neotropical 12 (2): 286-288.

Rocha-Mendes, F. \& G.V. Bianconi. 2009. Opportunistic predatory behavior of margay, Leopardus wiedii (Schinz, 1821), in Brazil Mammalia 78: 151-152. 10.1515/MAMM.2009.017: 10.1515/MAMM.2009.017.

SAldaÑa-VÁzqueZ, R.A. \& M.A. Munguía-Rosas. in press. Lunar phobia in bats and its ecological correlates: a meta-analysis. Mammalian Biology online. DOI: 10.1016/j.mambio.2012. 08.004.

SCARANO, F.R. 2002. Structure, function and floristic relationships of plant communities in stressful habitats marginal to the Brazilian Atlantic Rainforest. Annals of Botany 90: 517-524.

Skutelsky, O. 1996. Predation risk and state-dependent foraging in scorpions: effects of moonlight on foraging in the scorpion Buthus occitanus. Animal Behavior 52: 49-57.

Straube, F. \& G. Bianconi. 2002. Sobre a grandeza e a unidade utilizada para estimar esforço de captura com utilização de redes-de-neblina. Chiroptera Neotropical 8 (1-2): 150-152.

Thies, W.; E.K.V. Kalko \& H.U. Schnitzler. 2006. Influence of environment and resource availability on activity patterns of Carollia castanea (Phyllostomidae) in Panama. Journal of Mammalogy 87 (2): 331-338.

VizotTo, L.D. \& V.A. TADDEI. 1973. Chave para determinação de quirópteros brasileiros. São José do Rio Preto, Editora da Universidade Estadual de São Paulo, 72p.

ZAR, J.H. 1996. Biostatistical analysis. New Jersey, PrenticeHall, 662p.

Submitted: 08.X.2012; Accepted: 07.XII.2012. Editorial responsibility: Diego Astúa de Moraes 